\title{
Digital Rights Management: What the Consumer Wants
}

\section{Marc Fetscherin}

holds a Masters in Management from the University of Lausanne (HEC) and a MBA from the London School of Economics (LSE). He worked as a consultant at McKinsey \& Company where he got specialized in telecommunication and e-commerce. He holds a PhD from University of Bern. He also was a visiting researcher at the University of California at Berkeley as well as a fellow at Harvard University. Currently he is an Assistant Professor at Rollins College. He is the author of multiples articles, book chapters, conference proceedings and presentations and an expert in the field of digital content, piracy and Digital Rights Management.

Keywords: digital rights management (DRM), digital content, piracy, access control, usage control, survey

Abstract Digitization of content as well as the increasing piracy of content such as music, films or software demands appropriate protection against unauthorized access and use. Therefore, and in order to be successful, the management of rights of such content, often known under the umbrella term Digital Rights Management (DRM), is becoming increasingly important for today's digital asset managers. In the first part of this article, we provide a short introduction to DRM by outlining the entities, the various technologies used as well as usage restrictions that come with DRM. We also provide an example of a DRM used for movie downloads. What digital asset managers also have to understand are the consumer needs of those systems, in terms of technology requirement as well usage restrictions. The second part of this article provides first empirical results about the consumer acceptance of DRM systems. We outlined which technologies, as well as usage restrictions, which come with digital content, consumers accept and which might be obstacles for consumer for purchasing digital content. This article concludes by overcoming those obstacles, buying of digital content such as music, movies and software might become more attractive to consumers than copying. Journal of Digital Asset Management (2006) 2, 143-149. doi:10.1057/palgrave.dam.3650029

\section{INTRODUCTION}

\section{Definition}

Digital Rights Management (DRM) has been known by many names over the past few years. For example, a few large companies and public entities began researching into "Electronic Copyright Management" in the early 1990s $\left(\right.$ Bechtold $^{1}$ p. 2). One example of this is the Copyright in Transmitted Electronic Documents

Tel: +1407691 1759

Fax: + 14076461566

E-mail: mfetscherin@rollins. edu,

web: www.rollins.edu/inb (CITED) project funded by the EU. This "firstgeneration DRMS" focused on security and encryption, solving the problem of unauthorized copying by locking the content and limiting its distribution strictly to those who paid for it (Hauser and Wenz ${ }^{2}$ p. 208). Their capabilities were very limited compared to those of later DRMS.
The "second generation of DRMS," which has emerged in the past few years, takes the focus away from security, encryption and technology enforcement and extends its capabilities to management issues $\left(\mathrm{Guo}^{3}\right.$ p. 2). This important functionality of the management of rights is also indicated in the name of Digital Rights Management. Although it has been in existence for several years, there is no unique or standard definition of DRM (Fränkl and $\operatorname{Karpf}^{4}$ p. 25), nor has a single system emerged but rather many different ones (Owens and Akalu ${ }^{5}$ p. 64). None of the proprietary solutions available to date has managed to establish itself as the de-facto standard for DRM in the market place for the distribution digital content over the Internet (Bremer and Buhse ${ }^{6}$ p. 342). 
The Association of American Publishers (AAP) describes DRM as the technologies, tools, and processes that protect intellectual property during digital content commerce; Gordon ${ }^{7}$ defines it as a system of Information Technology (IT) components and services that strive to distribute and control digital content; $\operatorname{Rump}^{8}$ (p. 3) defines it as a type of server software developed to enable secure distribution, and perhaps more importantly, to disable illegal distribution; and Einhorn ${ }^{9}$ argues that DRM entails the operation of a control system that can monitor, regulate and price each subsequent use of a computer file that contains media content, such as video, audio, photographs, or print. Iannella ${ }^{10}$ argues that DRM covers the description, identification, trading, protecting, monitoring and tracking of all forms of usage over both tangible and intangible assets.

All these definitions have one element in common: they are concerned with the management of rights granted to the user for content. The term includes the word "digital" because Digital Rights Management manages rights on digital content. Hence, the word "digital" refers not to rights over information or digital content but to the medium in which the information is expressed. This is different than the management of digital rights, which is the way people sometimes interprets the term but which is incorrect, since there is no such thing as "digital rights" (Slowinski, ${ }^{11}$ p. 175).

\section{DRM entities}

There are three core entities involved in any DRM: The user, the content, and the rights, as shown in Figure 1. The USER can be any type of user, such as a publisher, a record company, a film studio, a corporate enterprise, or an individual. This entity creates the content, and the same or another uses the content. The CONTENT is any type of digital content, such as music, games, software, or a movie. The RIGHTS are the permissions, constraints, and obligations that are granted to or placed on the user and which apply to the content (Iannella ${ }^{10}$ ).

As shown in Figure 1, the content is created by an entity called the user. Either s/he also uses this content or the content is used by another user. The creator of the content, which can also

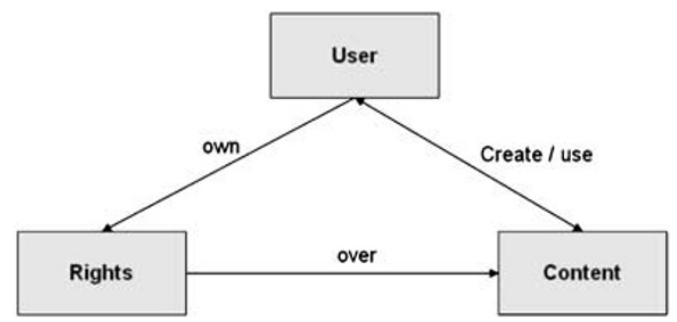

Figure 1: DRM Entities

use the content, owns certain rights that can be exercised over the content.

\section{Rights model}

The rights model allows expressions about the permissions or rights granted to the user in respect to the content, the constraints of the rights over the content, and the user's obligations when obtaining these rights (For example, how many times or how long these rights can be applied).

\section{Types of rights}

Expressions of these rights can quickly become very complex $\left(\mathrm{GuO}^{3}\right)$. However, it is critical to understand the expressiveness of the rights in computer language (Iannella ${ }^{10}$ ), as the rights model is at the heart of any Digital Rights Management System. Figure 2, adapted from Rosenblatt et al., ${ }^{12}$ (p. 62), illustrates the three main rights granted to a user for a certain type of content: render, transport, and derivative rights.

Render rights include the rights to print, view and play. Transport rights include those related to copying, moving, or loaning the digital content from one person, place or device to another. Derivative rights include those related to extracting, editing, or embedding the content. All kinds of manipulations of digital content are covered.

According to Rosenblatt et al., ${ }^{12}$ (p. 63), there is another right: The right to make a backup copy of content, or the utility right. This includes backup, caching and data integrity rights. Backup rights allow a copy of the content to be made for the sole purpose of restoring the primary copy if something happens to it. Caching rights 


\begin{tabular}{|l|l|l|l|}
\hline \multicolumn{2}{|l|}{ RENDER } & TRANSPORTATION & DERIVATIVE \\
\hline Pint & Copy & Move \\
Play & Loan &
\end{tabular}

Figure 2: Rights Model

permit items such as database caches and proxy servers to make local copies of content to improve system performance. Data integrity rights include the right given to users to create error-correction codes and other low-level means of ensuring that data is not corrupted.

\section{Rights constraints}

The second part of the rights model includes the limitations or constraints associated with the rights. These limitations can change relative to each of the three main types of rights. They can be limited by time or duration (for how long the content can be used), by number (how many times) or by location or device, for example. A rights expression may specify, for example, that a particular song can by played (ie render rights) a maximum of five times (ie limitation by number) and only for a week (ie limitation by time) for a fee of USD 2.00 (ie obligation to pay). Usually in such a case, if a right is not explicitly stated this means that the right has not been granted (Iannella ${ }^{10}$ ). This is a fundamental difference between buying music on a physical data carrier, such as a CD, under copyright law and downloading music from a website under license agreements or contract law. In copyright law everything is allowed except what is expressly excluded and limited by law, whereas when a license or contract law applies nothing is allowed except what is expressed in the rights language.

\section{Example of DRM}

What follows is an example of the application of a DRM system for online movies. We take movelink.com as an example as it is one of the first and most know website for movie downloads which uses DRM.

Movielink.com lets consumer legally download movies, TV shows and other popular videos for rental or purchase. The consumer can search and browse categories, pay with a credit or debit card. There are some software and hardware requirements. Figure 3 outlines the rental and purchasing details.

As Figure 3 shows, when the consumer rents the movie, he has the right to use it within the next 30 days. In other words, the consumer gets the right within the next 30 days to view the movie. Once he activates the playback, $\mathrm{s} /$ he has $24 \mathrm{~h}$ to watch it. When s/he purchases the movie, the consumer can play it as many times as possible and there is no time limit related to it.

The following Figure 4 outlines the various information the consumer gets when s/he downloads a movie. The information provided are, among others, the title, rental or purchase information, the duration of the movie, the download date and status (when the 30 days period starts).

Once the movie has been downloaded and the consumer is ready to watch the movie, the consumer gets informed again (see Figure 5) that $\mathrm{s} /$ he has $24 \mathrm{~h}$ to watch the movie once the playback has been activated. 


\section{Rental Details}

Rent without worry! Store for up to 30 days and watch during any 24-hour period.

STORAGE PERIOD: UP TO 30 DAYS

You're allowed to store a rental for up to 30 days after checkout. Once you start playback, you can watch it as many times as you like for 24 hours (see next section). Learn more

\section{VIEWING PERIOD: 24 HOURS}

Your 24-Hour Viewing Period begins when you click "Play Movie." Watch the movie as many times as you like within this period. You must

use the 24-hour Viewing Period by the end of the

Storage Period (noted on the movie details

page). Leam more

COST

Rental prices start at $99 \mathrm{c}$ per movic. No

subscription, membership fees or late fees.

\section{Purchase (Boto) Details}

Yours to keep! Watch as many times as you want, whenever you want.

During the BETA test, we are working to improve the purchase product and we welcome any feedback you might have.

STORAGE PERIOD: UNLIMITED

There is no limit to how long you are alowed to store purchases on your computer.

VIEWING PERIOD: UNLIMITED

When you purchase a movie download, it's yours to watch for as long as you want!

\section{COST}

Purchase prices start at $\$ 8.99$ per movie. No extra charges.

Figure 3: Rental and Purchase Rights

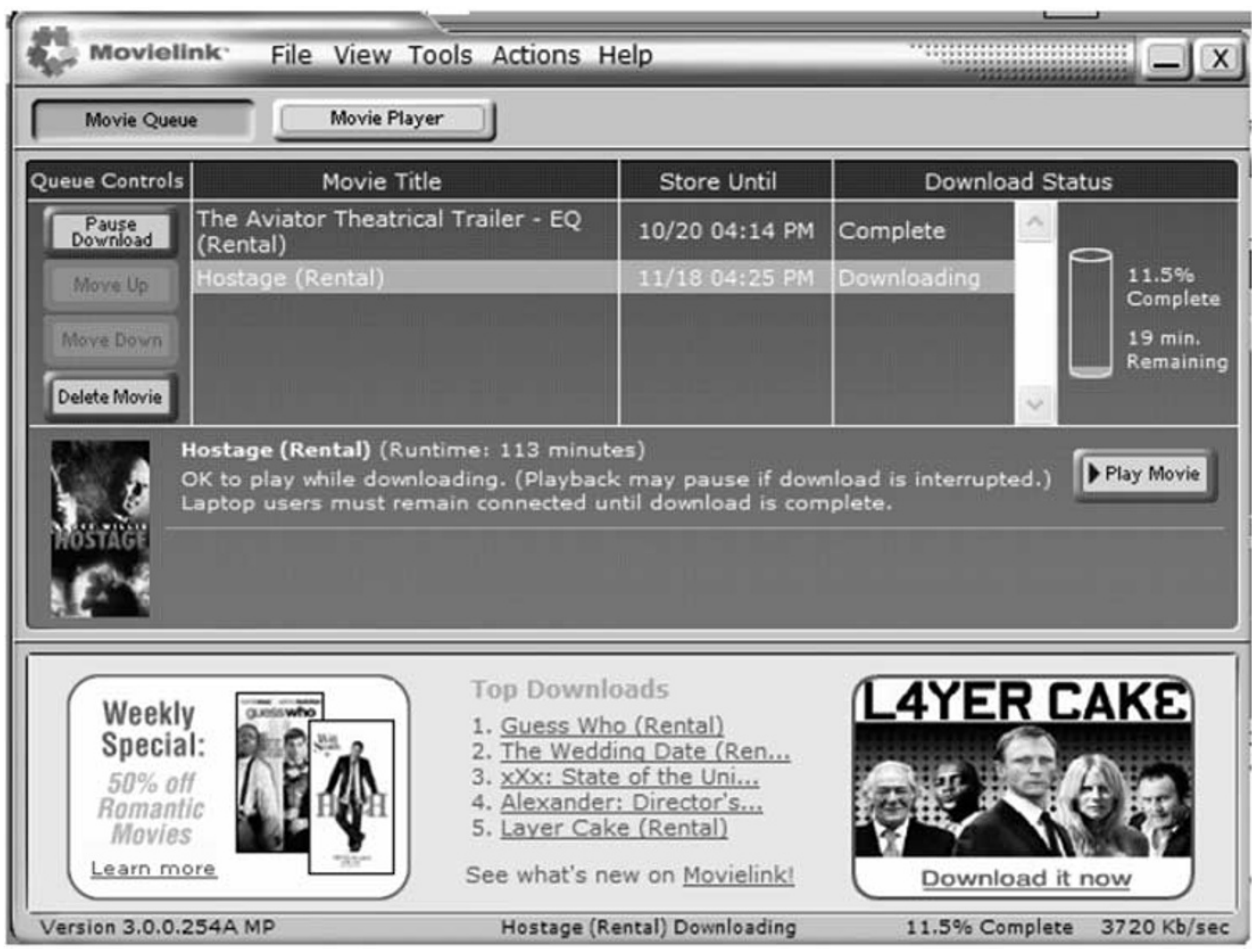

Figure 4: Screenshot Downloading

In this case, the consumer has the following rights as outlined in the previous section. The render right to view the movie, the transport right loan was granted, thus he cannot copy or move the file elsewhere. And after the expiration of the movie, the file that was stored on the consumer's computer will be deleted.

\section{CONSUMER ACCEPTNACE OF DRM}

\section{Understanding the consumer is key}

Consumers have various methods, channels, and possibilities for accessing, copying, using, sharing, and providing digital content. They can either 


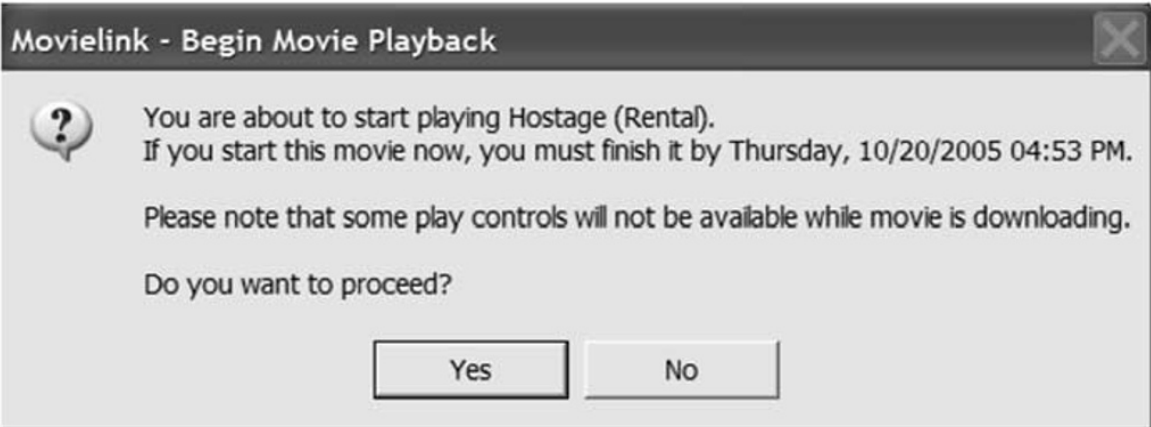

Figure 5: Information Usage Restrictions

purchase it legally as shown in the previous section, or copy it illegally over peer-to-peer networks for example. In that respect, content control is one of the most important aspects for content providers to distribute and sell successfully digital content as well as fight against piracy. When implementing such control systems like Digital Rights Management Systems (DRMS), it is unclear what the effects on consumer behavior are and whether consumers accept such restrictions and to what extend. It is, therefore, very important to understand the implications of the implementation of DRMS on consumer behavior, choices and the resulting demand for originals. The questions are: do consumers accept specific technology requirements for legal downloads and are there any differences between technologies? Do consumers accept usage or rights requirements on digital content and are there any differences? These questions will be discussed in this section of our article and we provide first empirical results about the consumer acceptance of Digital Rights Management Systems.

\section{Empirical study}

The study is based on a sample consisted of about 500 students, which is a sufficiently large number to represent the wide diversity of students adequately where we got 174 responses from the anonymous web-questionnaire. Although students do not represent the entire consumer segment, they account for a considerable proportion of all consumers of these products and are part of a consumer group in which copying and sharing of digital content is prevalent. Students are also part of the group that has already been identified as being more prone to copyright violations and piracy.

\section{Consumer acceptance of technological requirements}

There are a number of technologies used by DRMS that control the access to and the usage of digital content. The respondents were therefore asked which of the various technologies used would keep them from downloading content legally. A 5-point Likert scale was used to measure the acceptability of the various technologies from a consumer's point of view. The Likert scale ranged from 1 (strongly disagree), over 2 (disagree), 3 (indifferent/undecided), and 4 (agree) to 5 (strongly agree). The question asked was: Which of the following (technological) requirements would keep you from downloading legally? The technologies rated are shown in Figure 6 horizontally and their corresponding rating with the vertical value.

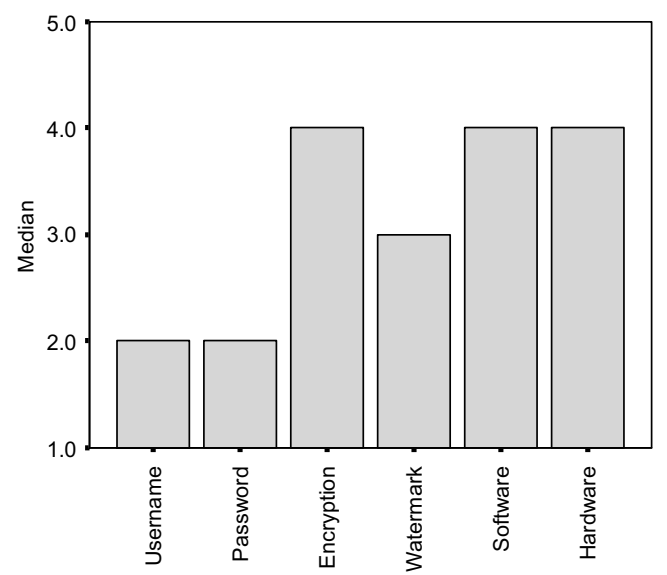

Figure 6: Technological Requirements 
Technologies perceived as obstacles form a consumer's perspectives are encryption and the necessity for specific software and hardware to use the digital content. The technologies less perceived as obstacles are the requirements for a username and a password. Respondents seem to be indifferent to watermarks or not having any clear idea. However, two questions arise when a Likert scale is used: does the question measure the perception in a useful way? Second, does the scale measure what it is meant to measure? In that respect we have to conduct a reliability and validity test of the answer provided. One way to measure the reliability and validity is by calculating a Cronbach alpha. We obtained a value of $\alpha=0.7970$, which is higher than the required $\alpha=0.6$, indicating that the results obtained are consistent and reliable.

\section{Consumer acceptance of usage restrictions}

Content providers grant consumers various usage rights and attributes of these rights for the digital content acquired, most often expressed in a rights model as shown in the previous section of this article. These rights can include the right to play, copy, burn or move the content where the attributes of rights might be the number of times a song can be copied onto a CD or for how long a movie can be watched. In the movielink.com example, the right provided was the right to view, where the attribute of those rights was a rental period of 30 days and a right to view it multiple times within $24 \mathrm{~h}$ once the playback started.

In most cases, these rights restrictions are expressed in a rights language such as $\mathrm{XrML}$ (Extensive Rights Markup Language) or ODRL (Open Digital Rights Language). The questions arise, which of these usage restrictions and underlying attributes of rights consumers are willing to accept? Are there differences for the various rights and if so, which? We asked therefore the respondents to rate a variety of statements, each including a type of right (play, burn and copy/move) and an attribute of that right. The question asked to respondents was: which of the following (rights) restrictions would keep you from downloading legally? The statements to be evaluated were: limited playability (in number), limited burning on a CD/DVD (in number), limited copying onto a
PC (in number), limited copying onto mobile devices (in number), limited encoding into other file formats (conversion), and limited playability (in time). Again, a 5-point Likert scale was used to rate these statements, ranging from 1 (strongly disagree) to 5 (strongly agree). The results are illustrated in Figure 7, where each statement is outlined on the horizontal line and the median value recorded for it provided on the vertical line.

According to Figure 7, any restriction on playability (either in the number or in time) will most probably be rejected by consumers, as consumers perceive it as a constraint in their use of the digital content. That is way in the example of movielink.com they provide two options for the consumer, one only to rent the movie for a limited time but for a cheaper value starting at USD 0.99, or another option to purchase the movie but at a higher price. The restrictions on the right to burn, copy onto a PC, and copy onto mobile devices are not perceived as main obstacles by respondents and might, therefore, be acceptable as also other studies have shown. Finally, respondents were indifferent about the possibility of converting media files from one format to another (ie encoding). As in the previous question, we conducted a reliability and validity test for the scale used and the answers provided. We arrived at Cronbach $\alpha=0.8646$, which is higher than the required $\alpha=0.6$ and thus indicates that the results obtained can be accepted as consistent and reliable.

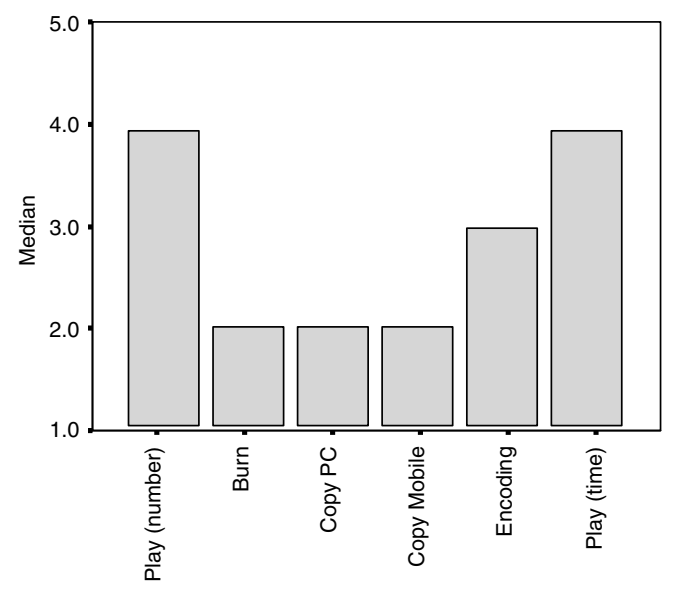

Figure 7: Usage Restrictions 


\section{CONCLUSION}

Content control is becoming increasingly important in today's wired and wireless world. Digital Rights Management System enable to control the access as well as the usage of digital content and enable on one hand content providers to fight piracy but also to monetize from digital content. On the other hand, these systems also restrict consumers in their usage of the purchased content and therefore reduce the consumer's utility of the legal download versus the copy. In that respect, understanding the consumer acceptance of those Systems is a key element in order to be successful in doing business with digital content. Our results have shown there are several technological and usage restrictions consumers do accept and some not. Understanding consumers and overcoming their concerns and purchasing obstacles may further improve the consumer experience with digital content and hence increase profitability of the business with digital content and therefore digital asset managers more successful.

\section{References}

1 Bechtold, S. Vom Urheber- zum Informationsrecht, Implikationen des Digital Rights Management. Verlag C.H. Beck oHG, München, 2002.

2 Hauser, T. and Wenz, C. DRM Unter Attack: Weaknesses in Existing Systems. In: Becker E. et al. (eds.), Digital Rights Management - Technological, Economic, Legal and Political Aspects. Springer, Berlin, 2003, pp. 342-362.

3 Guo, H. Digital Rights Management (DRM) Using XrML URL: http://www.tml.hut.fi/Studies/ T-110.501/2001/papers/guo.heng.pdf, [accessed: 2005-07-01]. 2001
4 Fränkl, G. and Karpf, P. Digital Rights Management Systeme - Einführung, Technologien, Recht, Ökonomie und Marktanalyse. Pg Verlag, München, 2004.

5 Owens, R. and Akalu, R. Legal Policy and Digital Rights Management. In: Kambhammettu S. (ed.), Digital Rights Management: Concepts and Applications. Le Magnus University Press, Hyderabad, 2005, pp. 64-85.

6 Bremer, O. and Buhse, W. Standardization in DRM: Trends and Recommendations. In: Becker E. et al. (eds.), Digital Rights Management - Technological, Economic, Legal and Political Aspects. Springer, Berlin, 2003, pp. 334-343.

7 Gordon, L. The Internet Marketplace and Digital Rights Management. In: Kambhammettu S. (ed.) Digital Rights Management: Concepts and Applications. Le Magnus University Press, Hyderabad, 2005, pp. 103-122.

8 Rump,N.Digital Rights Management:Technological Aspects. In: Becker E. et al. (eds.) Digital Rights Management - Technological, Economic, Legal and Political Aspects. Springer, Berlin, 2003, pp. 3-15.

9 Einhorn, M. Digital Rights Management and Access Protection: An Economic Analysis. In: Ginsburg J. et al. (eds.) Adjuncts and Alternatives to Copyright. Copy Co Printing, New York, 2002, pp. 1234-1240.

10 Iannella, R. Digital Rights Management (DRM) Architectures URL: http://www.dlib.org/dlib/ june01/iannella/06iannella.html, [accessed: 200507-01].

11 Slowinski, H. What Consumers Want in Digital Rights Management (DRM): Making Content as Widely Available as Possible in Ways that Satisfy Consumer Preference. In: Kambhammettu S. (ed.) Digital Rights Management: Concepts and Applications. Le Magnus University Press, Hyderabad, 2005, pp. 175-190.

12 Rosenblatt, B., Trippe, B. and Mooney, S. Digital Rights Management - Business and Technology. M\&T Books, New York, 2002. 